Indexaciones: Repositorio de Revistas UCR, DIALNET, Latindex, REDALYC Directorio y recolector de recursos digitales del Ministerio de Cultura de España, Directory of Open Access Journals. Diálogos Revista Electrónica de Historia ISSN 1409- 469X. Número especial 2008. Dirección web: http://historia.fcs.ucr.ac.cr/dialogos.htm

\title{
SEGURIDAD Y POLICÍA EN COSTA RICA POSTERIOR A LA GUERRA CIVIL DE 1948
}

\author{
Eduardo González Ayala
}

Bachiller en la Enseñanza de los Estudios Sociales. Estudiante de la Maestría Centroamericana en Historia y Profesor de la Sede de Occidente, Universidad de Costa Rica. Correo electrónico: edgonaster@gmail.com 


\section{Introducción}

El presente trabajo pretende llevar a cabo una síntesis de las transformaciones percibidas en la visión de la seguridad costarricense, así como en el posicionamiento político y el accionar de los diferentes cuerpos policiales en el país, en la segunda mitad del siglo XX. Para ello se establecen subperiodos y subtemas de análisis sustentados alrededor de la importancia que tuvieron para el país las problemáticas originadas por la Guerra Fría, y que denotan el manejo efectuado por parte del Estado de frente a dichas situaciones mediante la movilización de la policía, en ausencia de un aparato militar (al menos formalmente) que se encargara de la defensa. Los cuerpos policiales fueron entonces -y en gran medida continúan siendo- entes circunscritos al poder político. ${ }^{1}$

De esta forma el artículo transversaliza entre las nociones de seguridad nacional y seguridad interna. En el primer caso, el resguardo de las fronteras, sobre todo con Nicaragua, constituyó un punto neurálgico en el discurso de soberanía nacional, y para ello se volvió indispensable que la Guardia Civil jugara un papel cuasi-militar. En cuanto a la seguridad doméstica, su manejo manifiesta problemáticas relacionadas con corrupción y abuso de autoridad por parte de los cuerpos policiales, situaciones que denotan un nivel de profesionalización limitado; en este caso, se pasa del agente de pueblo y del Guardia Rural, a un concepto de policía más amplio y complejo, basado en la visión de seguridad sustentada en el combate a las drogas y en la seguridad ciudadana, que empiezan a consolidarse a partir de la década de 1980.

La labor se desarrolla utilizando como fuente primaria los periódicos La Nación y Adelante, documentos de archivo, principalmente de instancias institucionales, y dos entrevistas realizadas a expolicías que ocuparon puestos importantes en el entramado organizativo y administrativo de la Fuerza Pública, quienes vivieron gran parte de los acontecimientos aquí considerados. Se emplean además libros con carácter literario y de reportaje investigativo, en los cuales es posible observar críticas sobre el comportamiento policial, así como crónicas situadas en Internet que tratan sobre sucesos históricos de la década de 1950.

Las fuentes utilizadas permiten sobre todo ofrecer un panorama general del manejo de la seguridad y de cómo la policía es (in)capaz de llevar a la práctica las disposiciones dictadas "desde arriba”; no se trata entonces de analizar a profundidad la organización y obligaciones de las instituciones encargadas de la seguridad -entre ellas la policía-, sino más bien desvelar el

1 Mario Enrique Zamora Cordero, “La situación en Costa Rica. La perspectiva policial”, en Delito y seguridad de los habitantes, coord. Elías Carranza (México D.F., México: Siglo Veintiuno Editores, 1997$), 313$. 
discurso y la percepción en torno a la misma (sea ésta nacional o interna), interpretando cómo los cuerpos policiales se sitúan en medio de las instrucciones gubernamentales, o en qué medida hacen eco de éstas, en contraposición a los requerimientos e intereses de los diferentes sectores políticos y sociales, que en ocasiones apoyan al gobierno y en otras lo contrarían.

El trabajo inicia remitiendo al politizado ambiente existente en los años posteriores a la guerra civil de 1948, que se extendió inclusive con enfrentamientos bélicos hasta 1955. Luego trata la seguridad y el -en ocasiones infortunado- accionar policial en el ámbito interno, haciendo énfasis en las relaciones entre los policías y los ciudadanos en el contexto de una Costa Rica en el cual la dinámica de las poblaciones seguía siendo muy rural, donde las denuncias por abusos de autoridad y por el carácter violento de muchos oficiales fueron comunes. Finalmente, aborda la seguridad y las funciones de los cuerpos policiales a partir de 1970, en relación con problemáticas como narcotráfico y corrupción; además, se centra en detallar el manejo de la seguridad durante los conflictos centroamericanos, las posiciones políticas en torno a la guerra en Nicaragua y cómo se ven éstas reflejadas en la policía.

Asimismo, este artículo pretende en alguna medida evidenciar la necesidad de estudiar desde el punto de vista historiográfico, los entes represores del Estado y sus relaciones sociales; campo de investigación que autores foráneos han denominado historia social de la criminalidad, ${ }^{2}$ y que se ha dedicado a indagar el impacto social de los sistemas de justicia penal, las cárceles y las entidades de policía.

\section{Reminiscencias de la guerra civil: de diciembre de 1948 a enero de 1955}

Como una consecuencia de la guerra civil de 1948, en el mes de diciembre de ese mismo año un grupo de calderonistas provenientes de Nicaragua intentaron llevar a cabo una contrarrevolución, entendiéndola como un movimiento en el cual pretendían recuperar el poder que habían perdido recientemente con el levantamiento en armas de Figueres Ferrer.

Los simpatizantes del figuerismo denunciaron varias intromisiones de calderonistas armados, que con la ayuda de la Guardia Nacional nicaragüense, asesinaron a campesinos costarricenses y miembros de la Guardia Civil, como se les imputó durante el día de Navidad de $1948 .^{3}$

2 Clive Emsley, "La historia social evolutiva de la criminalidad y de los sistemas de justicia penal”, Revista de Historia (Costa Rica) 48 (julio-diciembre, 1996): 157.

3 Carlos Eduardo Saborío Alvarado, "El crimen del Codo del Diablo".

http://www.elespiritudel48.org/docu/h124.htm (Fecha de acceso: 17 de mayo 2008) 
$\mathrm{El}$ ambiente de resentimiento que campeaba en aquel entonces hace que las memorias existentes sobre dichos sucesos acusen sesgos considerables, los cuales se reflejan en las acusaciones sobre los excesos policiales ocurridos tanto en los gobiernos republicanos de Calderón y Picado, como en el periodo posrevolucionario gobernado por la Junta Fundadora de la Segunda República, referentes a robos, asesinatos y violaciones. Un episodio que refleja esta polémica fue el acaecido el 19 de diciembre de 1948, conocido como crimen del Codo del Diablo, cuando un grupo de autoridades figueristas asesinaron a sangre fría a varios opositores que habían estado presos en Limón. ${ }^{4}$

En la Escuela Militar de Guadalupe se entrenó la policía en los años posteriores a la abolición del ejército. Ello hace suponer la continuidad en los vínculos entre el antiguo entrenamiento militar y la preparación que empezó a recibir entonces la Fuerza Pública, tan es así que en muchas ocasiones se le denominó policía militar.

En abril de 1949 se intentó dar un golpe de Estado a Figueres encabezado por el coronel Edgar Cardona, quien fungía como ministro de Seguridad, “(...)hombre de toda confianza de don Pepe", ${ }^{5}$ lo cual refleja las tensiones existentes aún a raíz de la guerra civil. Cardona trató de aprovechar el estancamiento de tropas opositoras en Guanacaste, a las que ayudó a trasladarse a San José, no obstante fue traicionado por muchos de los combatientes reclutados para su causa y de filiación figuerista, por lo que debió rendirse.

Posteriormente, la invasión de 1955 fue uno de los acontecimientos que evidenció el manejo político de la seguridad del país y la actuación de la llamada policía militar. A inicios de enero de 1955 el gobierno de Figueres inició preparativos para contrarrestar un posible levantamiento armado desde Nicaragua, el que se denunciaba se llevaría a cabo con el apoyo de Somoza a los insurgentes, y del cual se rumoraba en corrillos oficiales que sería liderado por el propio Calderón Guardia.

La preparación de los combatientes estuvo motivada por el hecho de que éstos fueron reclutados desde diversas partes del territorio nacional, además a los comandantes se les brindó entrenamiento, y se sumaron al movimiento otros sectores políticos y policiales:

"Otros grupos de civiles y de policía, distintos al que se entrenaba en la

"Escuela Militar", a su vez se preparaban aceleradamente para enfrentar a la invasión que parecía inminente. (...) El Resguardo Fiscal, un cuerpo de policía $4 \quad$ Ibid.

5 Entrevista con Álvaro Sánchez Monestel, Desamparados, San José, 14 de mayo de 2008. 
especializado en la persecución del contrabando aduanero y de licores, al mando del Coronel Domingo García y de don Alberto Franco Cao, permanecía acuartelado y listo en su reducido local del Paseo de los Estudiantes. (...) La Guardia Civil, por su parte, permanecía en labor de vigilancia y de mantenimiento del orden en todo el territorio de la república; sólo algunos oficiales y tropa escogida de ese cuerpo participaron directamente, con otros de los grupos, en los encuentros armados que se produjeron en enero y febrero de 1955.”6

En cuanto al entrenamiento de los insurrectos, el mismo se llevó a cabo en Nicaragua. Por su parte el gobierno costarricense denunció que les brindaban ayuda no solamente Somoza, sino dictadores latinoamericanos como Trujillo, Batista y Pérez Jiménez.7 Quienes se adiestraron allí, viajaron primero a Honduras para despistar a las autoridades, y luego transitaron por tierra hasta llegar al sitio conocido como El Coyotepe:

"En el 55 seguidores del doctor Rafael Ángel Calderón Guardia, que se encontraba en Nicaragua, se entrenaron muchos costarricenses, yo no llegué hasta ese campo, muy superficialmente pasé por ahi, en El Coyotepe, que era una escuela militar allá por Rivas de Nicaragua. En El Coyotepe se prepararon un grupo de costarricenses que se querían venir a Costa Rica y dar un golpe de Estado ante el presidente de turno, Figueres."

Los calderonistas confiaban en derrocar a Figueres con el apoyo de los sectores opositores en Costa Rica y gracias al entrenamiento y aprovisionamiento procedente de Nicaragua. Ante tal amenaza y tras el descubrimiento de dicho campo de instrucción, el gobierno costarricense empezó a prepararse.

La prensa informó sobre las medidas tomadas por los entes gubernamentales, entre las cuales se encontraba el resguardo y vigilancia especial de sitios estratégicos como los aeropuertos, el desplazamiento de reservistas con entrenamiento militar y una denuncia interpuesta ante la Organización de Estados Americanos (OEA) contra Nicaragua. ${ }^{9}$

Las tropas gubernamentales se desplazaron hacia la zona norte de las provincias de

6 Joaquín Vargas Gené, "Santa Rosa 1955. Crónica de una batalla”.

http://www.editorialpln.info/publicaciones/Santa Rosa 1955.pdf (Fecha de acceso: 17 de mayo 2008)

$7 \quad$ Entrevista con Álvaro Sánchez Monestel, Desamparados, San José, 14 de mayo de 2008.

8 Entrevista con Max Cayetano Vega, San José, 27 de marzo de 2008.

$9 \quad$ La Nación, “La O.E.A. conocerá hoy la denuncia”, 9 de enero de 1955, 9. 
Alajuela y Heredia, con el fin de bloquear el paso a las fuerzas contrarias. El día miércoles 12 de enero "La Nación" titula: Estalló movimiento revolucionario. ${ }^{10}$ Tan sugestivo encabezado hacía referencia principalmente a un enfrentamiento que tuvo lugar en Ciudad Quesada, entre fuerzas oficialistas e insurgentes, cuyos nombres de dirigentes fueron publicados en la prensa; pugna que hacía prever nuevos disturbios en los días subsiguientes y llegó a convocar inclusive a sectores de la sociedad en brigadas civiles y a los cuerpos encargados de los servicios hospitalarios y las ambulancias.

El ambiente nacional se tornó entonces altamente belicoso, los discursos apelaban a una defensa a ultranza de la patria ante el invasor proveniente de un territorio extranjero. El Ministerio de Seguridad a través del Estado Mayor, realizó una convocatoria a la población instándola a la colaboración y el apoyo hacia las tropas oficialistas.

Ese mismo miércoles 12 de enero el presidente Figueres decretó la suspensión de las garantías individuales sustentadas en la Constitución Política ante la amenaza de una invasión foránea. El decreto fue publicado al día siguiente, mismo día en el que la prensa nacional informó acerca del bombardeo sucedido en la ciudad de San José, supuestamente llevado a cabo por parte de aviones extranjeros. También se hizo referencia a la toma de Ciudad Quesada por parte de las fuerzas gubernamentales, dando detalles sobre los muertos y heridos infringidos a la oposición, en contraposición a la única baja padecida por el oficialismo. ${ }^{11}$

Así, el combate en Ciudad Quesada fue explotado como una forma de convocar a los costarricenses a la lucha, resaltando la huída de los calderonistas entre las zonas montañosas de San Carlos, los cuales se replegaban esperando refuerzos provenientes de Nicaragua.

El comportamiento de la prensa nacional durante aquellos días (específicamente del periódico "La Nación”) fue de un respaldo total hacia el gobierno costarricense y hacia las acciones que éste puso en práctica para contrarrestar la pretendida "invasión”; la sistemática defensa de la legalidad y la democracia fueron argumentos esgrimidos constantemente por los periodistas para deslegitimar el movimiento insurgente.

Otro frente fue abierto en Guanacaste, donde los insurrectos tomaron La Cruz y en la hacienda El Amo establecieron su base de operaciones, en la cual recibían ayuda militar e inclusive a su pista de aterrizaje llegaron dos aviones de combate cedidos por Somoza. ${ }^{12}$

10 La Nación, “Estalló movimiento revolucionario”, 12 de enero de 1955, 5.

11 La Nación, “Ametrallada ayer San José”, 13 de enero de 1955, 12.

12 Joaquín Vargas Gené, "Santa Rosa 1955. Crónica de una batalla”.

http://www.editorialpln.info/publicaciones/Santa Rosa 1955.pdf (Fecha de acceso: 17 de mayo 2008) 
No obstante, la memoria del grupo vencido trata de invisibilizar o restar importancia a los sucesos ocurridos a inicios de 1955, pues la derrota significó un episodio que no era conveniente recordar y mucho menos darle publicidad o aceptar que fue un fracaso. Se trata entonces de disminuir la intensidad y el carácter real de los enfrentamientos:

“Hubieron ciertos combates, allá en el lado de La Cruz, frontera norte con

Nicaragua, y prácticamente no fue un movimiento que durara mucho tiempo

ni que fuera muy amplio, en diferentes lugares, no, simplemente ahí hubo unas

pequeñas escaramuzas y no fue tan larga la situación del 55."13

A pesar de esta posición de olvido y disimulo, los enfrentamientos se dieron, y el sábado 15 de enero de 1955 se llevó a cabo el combate más significativo de los acaecidos durante las pugnas de ese año, cuando tropas de la Guardia Civil costarricense se enfrentaron a los insubordinados en los alrededores de Santa Rosa. Las fuerzas gubernamentales, encabezadas por la Compañía Mario Charpentier, se encontraban ahí establecidas a la espera de instrucciones.

Conviene resaltar que en las tropas del gobierno habían dos personas que serían luego presidentes de la república: Francisco Orlich y Daniel Oduber; ambos se encontraban al mando de grupos de combate que en el desenlace de los acontecimientos provocaron un número considerable de bajas a los contrincantes. Posteriormente se llevaron a cabo luchas en otros sitios de Guanacaste, en las cuales las fuerzas del gobierno obligaron a retirarse a las tropas provenientes de Nicaragua.

La OEA empezó a jugar a partir de este momento un papel importante como mediador y ente que pretendía garantizar la seguridad en la zona limítrofe con Nicaragua. Estados Unidos vendió al país cuatro aviones por la simbólica suma de un dólar cada uno, con el fin de ser utilizados para la defensa ante posibles agresiones aéreas; paralelamente, las alianzas y posiciones internacionales empezaron a favorecer a Costa Rica, pues varios países latinoamericanos hicieron público su apoyo al gobierno de Figueres. ${ }^{14}$

Una de las consecuencias más destacadas de la batalla del 15 de enero en Santa Rosa por parte de la prensa, fue la muerte del periodista Jorge Vargas Gené, quien acompañaba a las tropas gubernamentales para informar respecto a los combates, junto a su hermano y también periodista Joaquín. La muerte de Jorge fue explotada como un icono de coraje y de defensa a ultranza de la patria, así como la del también periodista Óscar Cordero Rojas; las esquelas conmemorando su valentía fueron copiosas en los días subsiguientes.

13 Entrevista con Max Cayetano Vega, San José, 27 de marzo de 2008.

14 La Nación, "Patrullas de la O.E.A. cuidarán la frontera”, 18 de enero de 1955, 4. 
Este hecho particular viene a acentuar el argumento de que la prensa volcó su apoyo hacia el gobierno y hubo poco eco de la oposición en los medios. Tanto así que el fallecimiento del Teodoro Picado hijo, uno de los líderes de las tropas calderonistas, fue presentado como logro más que como pérdida y no se habló más sobre el asunto posteriormente.

En días subsiguientes a los eventos armados el clima político en el país se concentró en la exaltación de la victoria por parte del gobierno y un discurso tendiente a convocar a la población en pro de la unidad nacional, mediante la consolidación de la paz y la democracia en el país.

La deslegitimación de los "invasores" se dio inclusive por parte de antiguos aliados como los comunistas, que se refieren a ellos en términos de censura:

“(...) los calderonistas que se encuentran en Nicaragua después de haber participado en la expedición armada reciente, hemos sabido que éstos se encuentran en lamentable situación, que la mayoría carece de trabajo, de techo y hasta de comida y se ven precisados a vivir de la caridad pública." ${ }^{15}$

De esta forma, los comunistas dejan clara su separación del calderonismo y discurren sobre la inconveniencia de un movimiento armado que no hizo más que solidificar a Figueres en el poder y fortificar la influencia del imperialismo estadounidense sobre Costa Rica. Además, desde esta perspectiva, los calderonistas sirvieron de carne de cañón para Somoza y sus constantes disputas con el país.

\section{Seguridad en los pueblos: del Agente Principal de Policía al Guardia Rural}

La presencia de la policía en las diferentes comunidades costarricenses en las décadas de 1950 y 1960 está impregnada por un tinte político muy fuerte, el cual hace que los nombramientos se realicen a dedo de acuerdo con los designios del grupo dirigente que se encontrara en el momento en el poder.

Es posible vislumbrar disputas a lo interno de las comunidades por el comportamiento o la inclinación partidaria de algunos policías; tal es el caso de las quejas hechas llegar al despacho de Gobernación por vecinos que se oponían al nombramiento de algún policía por su afiliación política, como ocurrió en el distrito de Cirrí de Naranjo en 1953, cuando se denunció al nuevo policía de la comunidad por su reconocida filiación anti-ulatista. Para ello, se tramó inclusive un montaje de firmas, pues luego se demostró que muchas de las personas firmantes creyeron estar apoyando una causa distinta, no la destitución del oficial. ${ }^{16}$

15 Adelante, “Miserable existencia llevan los calderonistas en Nicaragua”, 21 de marzo de $1955,1$.

16 Archivo Nacional de Costa Rica (en adelante ANCR), Gobernación, Exp. 33949, (1953). 
Usualmente estos conflictos finalizaban cuando personeros del ministerio remitían la querella al jefe político local, quien era el encargado de iniciar un proceso de investigación al respecto. En otras ocasiones personas de una misma comunidad se organizaban para hacer sentir su malestar a las autoridades o ante quienes las nombraban; ejemplo de ello fueron las muestras de solidaridad para con un policía a punto de ser despedido, que le brindaron los vecinos de Desamparados en 1960, pues se manifestaban en desacuerdo con el hecho de que el agente fuese removido de su puesto. ${ }^{17}$

Dichas relaciones entre autoridades políticas, policías y ciudadanos, son significativas en la medida en que no remiten únicamente a la versión oficial, y es factible entonces prestar atención a la existencia de quejas de subalternos, e incluso de personas comunes, que se enfrentan al abuso policial y a lo que consideran decisiones erróneas de los políticos, lo cual permite clarificar en gran medida su participación en la dinámica de la seguridad acaecida al interior de las poblaciones costarricenses en las décadas en estudio.

Además, la vinculación de la seguridad con la praxis política evidencia una reivindicación de los derechos de los ciudadanos a partir de las relaciones que establecen con la autoridad, donde adquiere especial relevancia la posición ideológica de los actores sociales y las condiciones que propician el esparcimiento de dichas formas de pensar, a la par de la necesidad de combatir la delincuencia común.

Existía en las décadas de 1950 y 1960 la llamada Policía de Resguardo Fiscal, entidad que cumplía diversas funciones, entre las más importantes estaban: el control del comercio ilegal, supervisión de medidas y pesos, venta de licores, entre otros. Este ente policial era el más temido por su eficiencia y autoridad, decomisaba todo tipo de mercancía que no cumpliera con las especificaciones e imponía respeto ${ }^{18}$ además podía operar en regiones alejadas del Valle Central, si era necesario.

Prestaba servicio también la Policía de Villas y Pueblos, encargada de la vigilancia en las comunidades y de resolver asuntos relacionados con disputas de la propiedad. Este cuerpo era encabezado por el Agente Principal de Policía.

Dichos agentes, también llamados jueces de paz, eran sujetos con poca preparación, que en la mayoría de los casos no poseían ni siquiera estudios primarios, no sabían leer ni

17 ANCR, Policía, Exp. 14889, (1960).

18 Entrevista con Max Cayetano Vega, San José, 27 de marzo de 2008. 
escribir, ${ }^{19}$ y llegaban a esos puestos por compadrazgo político. Se integraban a la población a la cual eran asignados, y buscaban ganarse la confianza de los ciudadanos, pero sus métodos eran muy arcaicos y usualmente incurrían en abusos, dada la cuota de poder que se les asignada y que debían manejar con escasa o nula preparación.

El Agente Principal de Policía devengaba además un sueldo superior al de un policía común. No obstante, los ingresos de los policías rasos eran muy bajos, y ello evidentemente incidía en su preparación y capacidad de hacer frente a circunstancias complejas. Se planteaba entonces desde los entes gubernamentales

“La imperiosa necesidad de elevar el sueldo de la Policía de Villas y Pueblos.

Los Agentes Principales ganan 300.00 colones y los Policías simples (llamados auxiliares), 200.00 colones; estas sumas son las correspondientes a cada mes, y de ellas hay que hacer varias deducciones, lo que convierte el sueldo de cada servidor en aun menos de lo dicho. No cuentan con uniformes; ni siquiera distintivos; mucho menos armas o bastones." 20

De esta forma el ministro Joaquín Vargas Gené justificaba la pertinencia de crear una Ley Orgánica para el Ministerio de Gobernación y Policía en 1961, que contemplase las carencias reales de los oficiales en su diario quehacer y les permitiese una remuneración más justa, además de una mejor preparación. Así, se evidencian las carencias de la policía en aquel entonces, al no poseer ni siquiera lo básico, que en este caso serían los uniformes.

Lo anterior denota que los niveles de profesionalización policial a mediados del siglo XX eran muy deficientes, y ello se prestaba para abusos constantes por parte de las autoridades, como lo denuncia José León Sánchez en su libro La isla de los hombres solos: "Nadie tenía más poder que él en todo el pueblo por usar un revólver con el permiso del señor presidente. Era todo un Señor Autoridad y metía a la gente opuesta al Gobierno en un calabozo con las manos para atrás."21

La conjunción entre los intereses policiales y los del gobierno pasa por la necesidad de este último de mantener “a raya” a los opositores, que en aquel tiempo eran principalmente calderonistas y comunistas, los cuales a su vez rechazaban y criticaban el mandato de Figueres. 19 Ibid.

20 ANCR, Memoria de las labores realizadas en los ministerios de Gobernación y Policía, Justicia y Gracia. Del $1^{\circ}$ de mayo de 1960 al 30 de abril de 1961, Colección Memorias, № 268, (1961), f. 91.

21 José León Sánchez, La isla de los hombres solos (San José, Costa Rica: Editorial Costa Rica, 1984), 2021. 
El papel de la opinión pública es también un elemento a tomar en cuenta, sobre todo si se relaciona con la efectividad de los cuerpos policiales para enfrentar la criminalidad y dilucidar los casos más comprometedores, por ejemplo los asesinatos.

Al interior de la policía la legitimidad frente a la ciudadanía se convierte en un elemento neurálgico, y por ello se hace necesario justificar sus actividades mediante la captura y punición de los criminales. No obstante, la corrupción en ciertos grupos policiales llevó a algunos de sus miembros a pasar por alto las normas de su ocupación y a infringirlas con tal de obtener reconocimiento.

Así ocurrió en casos relacionados con asesinato, cuando se buscaban testigos falsos con el fin de inculpar y encarcelar a personas por crímenes que no habían cometido, como se evidencia en el caso investigado por Enrique Benavides en su obra El crimen de Colima; aquí se detalla una espantosa práctica policial, en la cual los oficiales y detectives, cuando no tenían pistas de quién o quiénes podrían ser los autores reales, detenían a personas inocentes:

“(...) confesó que si había declarado en la causa de los hermanos Zamora en la forma que lo había hecho, fue porque había sido obligado por la Dirección de Detectives, quien junto con sus subalternos le dijeron que si no declaraba así lo metían a la cárcel. Agregó que por miedo había declarado denunciando falsamente a Villalobos y compañeros, pero que no sabía nada de ese asunto y que estaba dispuesto a retractarse, pues esa gente estaba presa por su culpa; dijo además que si le daban treinta mil colones se echaba toda la responsabilidad encima y esa gente salía.”22

Actuaciones como ésta, donde se declara bajo amenaza, represión y violencia constantes, denotan el grado de corruptividad de las autoridades, al punto de que el supuesto testigo al llevar a cabo su rectificación, enfatiza que si le dan dinero él mismo puede confesarse culpable, lo que hace pensar que la práctica del soborno era común entre los oficiales.

La población civil llegó a experimentar más que respeto, un gran temor hacia la policía, pues no era extraño que a los detenidos los golpearan o torturaran para conseguir una confesión que, dadas las circunstancias en las cuales era obtenida, usualmente no correspondía con la realidad y el reo se declaraba culpable para evitar seguir siendo maltratado o bajo promesas falaces de un trato absolutorio para un crimen que no había cometido:

22 Enrique Benavides Chaverri, El crimen de Colima. Un error judicial (San José, Costa Rica: Imprenta Vargas, 1966), 46-47. 
"Las “confesiones" se producen, pues, estando los reos en la Academia Militar, incomunicados y sin ninguna clase de garantías legales, a merced de los oficiales y los detectives, quienes asumieron la tarea de hacer cantar a los reclusos valiéndose para ello de los conocidos recursos de violencia física, como baños helados a altas horas de la noche, punzadas de bayoneta, presión sobre los órganos genitales, amenazas, promesas de ayuda, lecturas de supuestas declaraciones en que un inculpado aparecía haciendo responsable de los hechos a otro, etc." ${ }^{23}$

Además, el trato en los sitios de detención era deshumanizado y en muchas ocasiones el preso no sabía por qué motivo lo habían detenido. Queda evidenciado que la Escuela Militar de Guadalupe funcionaba, además de cuartel y sitio de instrucción, como emplazamiento de interrogatorios y torturas.

Las agresiones de los oficiales hacia los ciudadanos eran también comunes y denotan el grado de agresividad existente en el trato policial, como lo evidencia el caso de una señora agredida en 1959 cuando intentaba vender sus mercancías en los pasillos del mercado central:

"Se quejó la denunciante, ante nuestros redactores, que había sido batoneada, cogida del pelo y agredida de tal forma que ello produjo la indignación de la gente que presenció el hecho. En el cuerpo presentaba los hematomas de los batonazos que le dieron." 24

La indignación y el temor popular tendían a acrecentarse efectivamente por las actuaciones violentas de los oficiales:

“(...) vociferando, hecho un energúmeno, irrumpió la morada con sus guardas atropellando uno de ellos violentamente a un niño que se encontraba en torno a su madre, y profiriendo frases groseras contra la señora, registraron la casa." 25

El nivel de escolaridad tan bajo de los policías favorecía estos desmanes; muchos abusos se cometieron en la persecución y el apresamiento de personas que se dedicaban a destilar el famoso guaro de contrabando, quienes eran objeto de acoso y represión por parte del Resguardo Fiscal y de la Policía de Villas y Pueblos, por ser la mencionada una actividad ilegal que competía con el monopolio de la Fábrica Nacional de Licores.

23 Ibid, 79-80.

24 La Nación, “A segunda orden el Guardia Civil que agredió a una señora”, 20 de enero de 1959, 10.

25 Adelante, "Policías contra trabajador bananero”, 27 de marzo de 1955, 2. 
No obstante, la relación de fuerzas entre estos grupos policiales cambió en 1970, cuando el ministro Carlos Manuel Vicente propició la creación de la Guardia de Asistencia Rural, en demérito del Resguardo Fiscal y de la Policía de Villas y Pueblos.

Este proyecto se llevó a cabo desde el Ministerio de Gobernación, con poca injerencia por parte de la cartera de Seguridad. La discusión en el país se centró en las potestades que tendría el nuevo ente para evitar roces con la Guardia Civil y para conseguir que cada cuerpo policial desempeñara adecuadamente sus funciones.

Los policías rurales tendrían por ley que haber aprobado al menos el sexto grado y estar comprometidos a ayudar a la comunidad en las tareas en que fueran asignados, no sólo el manejo de la seguridad, sino además la alfabetización de adultos, el cuidado de propiedades, cultivos y ganado, el apoyo a programas de salubridad, la colaboración en proyectos de infraestructura comunal, entre otras funciones similares. ${ }^{26}$

De esta forma, la lógica del manejo de la seguridad ciudadana a nivel gubernamental establecía dos frentes bien definidos: las zonas urbanas, a cargo de la Guardia Civil, y las regiones rurales, bajo la vigilancia de la recién constituida Guardia Rural.

\section{Los dilemas de la seguridad a partir de 1970: corrupción, narcotráfico y el conflicto armado en Nicaragua.}

Las décadas de 1970 y 1980 estuvieron permeadas fundamentalmente por dos lunares o preocupaciones en relación con la seguridad en Costa Rica: el tráfico de drogas (aunado al lavado de dinero), y los movimientos revolucionarios y contrarrevolucionarios en Nicaragua.

La policía costarricense en la década de 1970 empezó a tomar muy en serio el combate a la venta de estupefacientes en diversas regiones del país, sobre todo la droga más común en aquel entonces: la marihuana. En mayo de 1970 las autoridades fiscales y policíacas iniciaron una fuerte campaña antidrogas por todo el país, que pretendía reducir la venta de marihuana y a la vez detener a aquellos traficantes conocidos, sobre todo en las zonas conflictivas de San José y Limón. ${ }^{27}$

Precisamente para efecto de apresar a los dispensadores de drogas fue creada en 1970 la llamada Policía de Narcóticos. Este ente se encargaba, además de perseguir, de advertir otro

26 Mainor Morales Villegas, “Creación y evolución de la Guardia de Asistencia Rural”, en Ministerio de Gobernación y Policía: 150 años de historia (San José, Costa Rica: Imprenta Nacional, 1994): 339-343.

27 La Nación, "Batida contra la marihuana se inició en todo el país”, 12 de mayo de 1970, 10. 
tipo de fraudes, entre los que se destacaban la falsificación de moneda, tanto nacional como extranjera, y su puesta en circulación, como sucedió en un operativo efectuado en Barrio Cuba: "La policía ocupó tintas, papel especial cortado al tamaño de los billetes y numerosas copias de papel moneda nacional...”28

No obstante, el énfasis dado en el seguimiento de los distribuidores de drogas hace que este periodo sea relevante; fue entonces cuando se suscitaron en el país una serie de asesinatos en los cuales se especuló que podrían estar involucrados miembros de la policía. A estos crímenes acaecidos en los primeros años de la década de 1970 se les conoce como las muertes extrañas, pues nunca llegaron a resolverse por parte de los detectives o las autoridades judiciales.

En este punto conviene hacer referencia a la denuncia que realizaron dos hermanos de apellido Romero sobre un asesinato muy particular que ocurrió en 1973, a través del libro titulado El caso Chemise. Dicha narración posee un carácter político marcado e involucra a quien, en el momento de publicación de la obra, era un factible candidato a la presidencia de Costa Rica por uno de los partidos tradicionales.

El involucramiento de José María Figueres Olsen como posible homicida, no es el punto neurálgico. Interesa más interpretar los vínculos existentes entre los políticos, la Policía de Narcóticos y los comerciantes de droga; circunstancias que en la mayoría de ocasiones favorecían la impunidad, la corrupción y el abuso de autoridad.

Más específicamente, la descripción que dan los autores del mayor Álvarez, encargado en aquel entonces de la Policía de Narcóticos, ofrece una imagen poco alentadora:

"Era muy poco culto y preparado.

Tenía muchas relaciones políticas, lo que le permitió un rápido ascenso.

Era sumamente violento, lo que le ocasionó diversas demandas penales."29

Esta sinopsis resume el comportamiento del director de uno de los cuerpos policiales que, pese a su reciente fundación, parecía llamado a cumplir una función trascendente; la descripción es reveladora, pues demuestra cómo los vínculos políticos pesaban más que la capacidad de los individuos, y cómo no existía una legislación pertinente que estableciera condiciones mínimas a los policías para poder desempeñar ciertos cargos. Lo anterior daba como consecuencia lógica que su nivel profesional fuese demasiado restringido y su propensión al uso excesivo de la fuerza, incontroladamente alto.

28 La Nación, "Policía de narcóticos descubrió falsificación de billetes ayer", 9 de setiembre de $1970,10$.

29 David Eugenio Romero y José Manuel Romero, El caso Chemise (San José, Costa Rica: Talleres Gráficos de Guilá, 1991), 64. 
Como ejemplificación de las escasas calidades de los oficiales, es factible esbozar una denuncia de las acciones incorrectas que se patentizaban en las causas penales contra dichos policías:

“Todas ellas traslucían, actos de corrupción, sobornos, torturas y abusos sexuales de menores.

Todas señalaban como responsables de estas prácticas a distintos miembros de la Sección de Narcóticos.

Así agentes de esta sección proveían de marihuana y LSD a los consumidores para tener acceso carnal con jovencitas; otros consumían drogas con los individuos que aparentemente combatían; otros redistribuían las partidas capturadas; otros hacían "cobros" para no obstruir el "tráfico"; y luego estaba Álvarez con su cuota de violencia." ${ }^{30}$

Tales eran los comportamientos de oficiales que se suponía debían combatir la venta de drogas. Figueres Olsen era para entonces teniente de la mencionada sección y gustaba del accionar policial que podía realizar con total libertad, al amparo que le brindaba el hecho de ser el hijo del Presidente.

La imbricación de los comerciantes de marihuana con las autoridades que pretendían combatirlos, deja clara la situación arcaica en el manejo de la policía en aquellos años. Se expresa la incapacidad de los gobernantes y de los mismos entes de seguridad para llevar a cabo un saneamiento de dichas prácticas policiales que llegaron a arraigarse entre los agentes, los cuales buscaban un beneficio inmediato y personal en detrimento del cumplimiento de sus obligaciones.

A finales de la década de 1970, todos los problemas relacionados con seguridad se enfocaron en un solo espacio: Nicaragua. La seguridad doméstica se trasladó a un segundo plano, dando paso nuevamente a la seguridad nacional como eje del discurso político, ante el riesgo que significaban los conflictos armados en el vecino país.

En 1979 el llamamiento a la defensa del territorio nacional volvió a la palestra, sobre todo porque en el mes de junio la Guardia Nacional de Somoza atacó la zona norte del país, específicamente la región de Cabalceta, a un kilómetro de la frontera. ${ }^{31}$

Las medidas de vigilancia en los aeropuertos y zonas limítrofes se intensificaron; el $30 \quad$ Ibid, 66 .

31 La Nación, “Artillería nicaragüense volvió a atacar la región de Cabalceta”, 24 de junio de 1979, 22A. 
temor hacia una invasión desde Nicaragua estaba latente e hizo necesario el desplazamiento de la Guardia Civil cerca de la frontera, incluso al punto de establecerse planes de evacuación en la zona de La Cruz. Mientras tanto, la prensa azuzaba el sentimiento de recelo hacia un posible ataque contra el país:

"Tanto las autoridades costarricenses, como los voceros del Frente Sandinista de Liberación Nacional, han confirmado y reiterado la información de que unos 300 guardias nacionales de Nicaragua tratan de tomar por asalto el puesto fronterizo de Peñas Blancas. (...) se supo que el comando costarricense de la región había recibido también más armamento necesario para repeler un eventual ataque de la Guardia Nacional." 32

Es conocido que el territorio costarricense en aquel momento sirvió a la causa revolucionaria sandinista, situación facilitada gracias a la simpatía del gobierno de Carazo por el sandinismo; dichas operaciones se dieron sobre todo en la región de Guanacaste: "En ese Pelón de la Altura siempre se estableció que fuera un lugar de entrenamiento, y de hecho, ahí estuvo Edén Pastora y aproximadamente como unos cuatrocientos sandinistas." ${ }^{33}$

Ya en la década de 1980, y tras haberse consumado el triunfo de la revolución en Nicaragua, la región fronteriza costarricense continuó siendo escenario de una política de contención de amenazas, en la cual la policía jugaba el papel central. A pesar de la pretendida política de neutralidad del presidente Monge, los contrarrevolucionarios utilizaron el territorio nacional como base de operaciones, tal y como lo habían hecho los sandinistas años atrás.

Las relaciones entre los gobiernos de Monge y Ortega se debilitaron, a tal punto que hubo momentos de gran tensión cuando los sandinistas bombardearon partes del territorio nacional buscando impactar a los “contras", en mayo de $1984 .^{34}$

Grupos de extrema derecha opositores al sandinismo en el país, como el Movimiento Costa Rica Libre, llevaron a cabo una campaña agresiva que incitaba a luchar contra cualquier posible incursión del gobierno nicaragüense o del comunismo en territorio nacional, al tiempo que criticaban férreamente la política de neutralidad de la administración Monge, calificándola de cobarde y contraria a los intereses de la patria.

De esta forma, el conflicto fronterizo en la zona norte propició que el país se volviese

32 La Nación, “Guardia Civil espera llegada de patrullas nicaragüenses”, 30 de junio de 1979, 19 A.

33 Entrevista con Max Cayetano Vega, San José, 27 de marzo de 2008.

34 La Nación, “Canciller dice que relación con los nicas es gravísima”, 2 de mayo de 1984, 12A. 
más dependiente de la injerencia exterior estadounidense, y que la influencia militar sobre los cuerpos policiales ticos aumentara en consonancia con el incremento de recursos para la defensa provenientes de la nación del norte en aquellos años. ${ }^{35}$

La situación vivida en Nicaragua favoreció la militarización de los cuerpos policiales en Costa Rica, a la par de realidades como el narcotráfico y el trasiego de armas. Se buscó desde instancias institucionales capacitar mejor a la policía para un eventual enfrentamiento:

"Es evidente que el gobierno tiene conciencia de la necesidad de dar mayor formación policial, que vaya acorde a la realidad nacional y con el ambiente de crisis regional en que se vivía entonces. Así se llega en 1983 a crear la Academia de la Fuerza Pública Francisco J. Orlich, que se encuentra ubicada en San Antonio de Belén y que funciona dando formación especializada a la policía nacional y para lo cual siempre ha contado con la colaboración de países amigos.”36

Evidentemente, esos “países amigos” son naciones con gran experiencia militar, como ocurrió en la década de los ochenta con la ayuda ofrecida por el gobierno venezolano, y como ha ocurrido desde entonces con las capacitaciones norteamericanas y los cursos recibidos por policías costarricenses en el exterior, por ejemplo en la Escuela de las Américas.

Asimismo, durante la administración Monge se estableció la Escuela de Entrenamiento El Murciélago, ubicada en Guanacaste, que pretendía brindar una mayor capacitación a los miembros de la Fuerza Pública y una formación militar más depurada al personal del Ministerio de Seguridad. ${ }^{37}$

Se desprende de lo anterior que los cuerpos policiales costarricenses comenzaron a recibir un fuerte entrenamiento en cuanto a operaciones, tácticas de enfrentamiento y manejo de armas, que ha sido utilizado en años recientes para tratar de frenar el trasiego de drogas y armas, y que ha desembocado en que sectores de la policía, como la reconocida Dirección de Inteligencia y Seguridad (DIS), suscrita al Organismo de Investigación Judicial, posean un carácter marcadamente militarizado.

35 La Nación, "EE.UU. aumentará ayuda militar para Costa Rica”, 3 de mayo de 1984, 12A.

36 Ileana Valerín y Fabiola Tellini, "El conflicto de la frontera norte: diversificación de los cuerpos de seguridad pública en Costa Rica (1978-1990)” (Tesis de Licenciatura en Historia, Universidad de Costa Rica, 1996), 241.

37 Ibid, 243. 


\section{Conclusión}

La Guardia Civil y los demás cuerpos policiales costarricenses cumplieron, en los años inmediatos a la abolición del ejército, un papel fundamental como defensores de la seguridad nacional. El ejemplo más significativo se observa en los enfrentamientos de 1955 en la zona norte y Guanacaste, donde fue necesaria la coordinación de los diferentes grupos policiales para hacer frente a la amenaza de invasión y repeler los ataques de los calderonistas provenientes de Nicaragua.

Lo sucedido en el 55 refleja las disputas irresueltas en la década de 1940, pero con una inclinación diferente en un momento álgido de la guerra fría, en el cual el gobierno figuerista buscaba resaltar su anticomunismo y a la vez repelar la influencia de dictaduras que, como en el caso de Somoza, contaban con el apoyo tácito de Estados Unidos.

En cuanto al accionar policial vinculado a la seguridad interna, es decir, con los cuerpos policiales que estaban en contacto con la población, presentaron entre 1950 y 1980 particularidades como: un nivel muy bajo de profesionalización, reflejado a través de una mínima escolaridad, bajos salarios y equipamiento deficiente; un trato violento respecto a la población en determinadas circunstancias, marcados síntomas de abuso de autoridad y una corrupción que afectó el desempeño de entes específicos con funciones policiales, como la Dirección de Detectives y la Policía de Narcóticos; finalmente, una fuerte dependencia hacia el gobierno de turno y a las disposiciones tomadas por éste, convirtiendo a la policía en un ente politizado, encargado usualmente de ejecutar la represión política.

Los conflictos en Nicaragua, que a finales de la década de 1970 comenzaron a tener un mayor impacto en el país, trasladaron las preocupaciones en torno a la seguridad del ámbito doméstico al plano internacional. Nicaragua se convirtió nuevamente en una amenaza palpable, primeramente por la tiranía de la dictadura de Somoza, y posteriormente por la iniquidad del gobierno sandinista. 
Los cuerpos policiales costarricenses cumplieron en este contexto la labor de entidades de contención, atentos siempre a un posible enfrentamiento con las fuerzas invasoras nicaragüenses. A partir de entonces, la influencia estadounidense sobre las temáticas relacionadas con seguridad y policía en Costa Rica, no ha hecho sino ir en aumento, en materia de financiamiento, capacitación y aprovisionamiento, en un proceso de progresiva militarización.

El narcotráfico se convirtió en una preocupación medular, dada su rápida expansión y su capacidad para corromper a las personas. En la actualidad los temas más álgidos en materia de seguridad tienen que ver con el tráfico de drogas y con el incremento en la delincuencia que atenta contra la propiedad y la vida de los ciudadanos, acuciada por la propaganda constante en los medios de comunicación. 